\title{
Research on The Design of Children's Toys and Teaching AIDS Based on Sound Science
}

\author{
Hong-he $\mathrm{Gao}^{1}$, Jin-hua $\mathrm{Fu}^{1}$, Xiao-cheng Xing ${ }^{1}$ \\ ${ }^{1}$ School of Art\&design, Liaoning Shihua University, Fushun, Liaoning,113001, China
}

\begin{abstract}
Playing teaching aids is an indispensable auxiliary tool for children's growth and development, and hearing is an important way for children to perceive and understand the world. According to children's learning and cognitive laws, and in combination with the design concept, educational function and application orientation of play AIDS, a series of play aids products, such as "audio tumbler", "microphone" and "simulated tympanic membrane vibration", are designed to deeply reflect how the sound is generated, bringing a new knowledge system for children, making learning more interesting and interactive It can help to fully cultivate children's interest, promote children's development and improve their interest in learning.
\end{abstract}

\section{Introduction}

Play teaching aids play an auxiliary role in children's growth and development. With the progress of society and the development of the times, people are more and more aware of the importance of play teaching aids in children's growth. At the same time, more and more attention is paid to providing various play teaching aids for children. As an important teaching tool, playing teaching aids can help children better understand the world, and it is also an effective way to learn knowledge. With the arrival of the second child era, the number of children in China has increased dramatically. Popular science teaching aids are springing up, and voice teaching aids are gradually increasing. Because children's perception of sound starts from birth, hearing is an important way for children to perceive and understand the world, so it is necessary to play with audio teaching aids. However, there are many problems in the existing audio playing teaching aids, such as the knowledge transfer is too single, the form is relatively rigid, which is not conducive to children's cognition and so on. Therefore, the design of audio play teaching aids aiming at children's science popularization is of great significance for children's education.

\section{Teaching aids toys products and their value}

\subsection{Teaching aids toys products}

As the name implies, teaching aids toys are an organic co mbination of toys and teaching aids, and have the dual function of toys and teaching aids. Teaching aids toys refer to a complex with good interactivity and fun, which can not only carry out teaching activities and impart knowledge, but also have fun and playability, and can be used as toys. In the past, the teaching aids toys refer to toys and teaching aids used by children in games and life. They only play a role in explaining knowledge. The research on teaching aids toys is mainly limited to functionality, and often overlooks interaction and fun. Teaching aids toys have positive significance and value for the development of children's physical and psychological functions, language, behavior, learning ability, etc. ${ }^{[1]}$ Dewey pointed out in "Democracy and Education": "People's initial understanding, the most ingrained knowledge is knowledge about how to do something ${ }^{[2]}$." We have to design from the children's life experience Production, further optimization and improvement of interactive fun teaching aids. We must proceed from the children's life experience, design and produce, and further optimize and improve the design of interactive teaching aids toys. Alternative methods, amplification methods, and conversion methods can be applied in the design, and the design can be carried out with a starting point that children can understand.

Therefore, the study of children's cognition of sound is of great significance to the development of scientific teaching aids toys. At the same time, the application of teaching aids toys is beneficial to the development of children's knowledge, abilities, interests, emotions, and body and mind. Sound-type interactive teaching aids toys are conducive to mobilizing children's enthusiasm and initiative. The sounded teaching aids toys for science popularization should have the situation of displaying knowledge points, as well as having interesting and interactive characteristics. It helps to cultivate children's imagination and improve children's innovative thinking. Imagination is the source of creativity. Only when

*Corresponding author's e-mail: red_river@126.com 
children have imagination can they have more possibilities for creativity.

\subsection{Design value of teaching aids toys products}

At present, the society is changing rapidly, science and technology are advancing rapidly, and people need more and more skills for survival. The current status of children's education directly affects the quality of future population resources, so children's education is highly valued by the whole society. Children's toys and teaching aids are important learning resources in educational activities, so they become important graspers. In the context of quality education, the novelty and originality of teaching aids toys are increasingly valued by people. According to children's physical and mental development characteristics and the needs of education, designing educational, scientific, interesting and interactive teaching aids toys can greatly meet the needs of children's growth. Similarly, such teaching aids toys can also cultivate children's desire to explore and promote the healthy development of children's thinking.

\section{Research status}

\subsection{Research on the status quo of teaching aids toys in foreign countries}

Many countries like the United States, Germany

and Japan attach great importance to allowing children to experiment with their own hands, to gain knowledge and experience the fun of learning science in practical exploration. They emphasize that children are required to "do" science, not just use their ears to "listen" to science and "see" science with eyes. We should guide children to conduct practical activities such as experiments, operations, and production according to the content of science education, so that children can use their hands and brains to acquire scientific knowledge skills, cultivate scientific spirit and attitude to shape scientific values. ${ }^{[3]}$ At the same time, the development and design of foreign audio teaching aids toys can meet children's interests in sound, melody and rhythm, music entertainment, etc., and can integrate knowledge points very well. A teaching aids toy has multiple knowledge points, both fun and interactive, not only can effectively convey knowledge, but also enables children to learn in it.

It can be seen that the countries that value education in the world are more enthusiastic about the development of teaching aids toys. Teachers in developed countries such as the United States, Germany, and Japan have long realized the unique charm of using teaching aids toys, so they are constantly innovating and passionately integrating traditional teaching aids with modern technology, resulting in a variety of new teaching aids toys. It makes the variety of teaching aids toys rich and diverse, with multimedia and other professional software to cooperate with learning. Overall, the category is relatively complete.

\subsection{Research on the status quo of teaching aids toys in China}

Affected by the test-oriented education, the production and use of teaching aids toys in China have not received enough attention. There are many domestic research papers on the design of teaching aids toys, but they are mainly based on the research of homemade teaching aids toys. According to the research of the data, it is found that the model teaching aids toys are one of the most frequently used teaching aids toys. The model playing aids toys are deeply loved by teachers and children because of their intuitiveness, ease of storage and ease of production. However, with the deepening of innovative ideas in the field of knowledge, model teaching aids toys are also facing the problem of innovation. ${ }^{[4]}$ The design of existing teaching aids toys mainly focusses on the discussion of the specific operation technology and knowledge points. There are very few teaching aids toys developed from children's perspective to popularize science, especially the audio-based teaching aids toys. See Figure 1. For example, in the course of learning how sound is produced, the teaching aids - tuning fork has been used without further innovation, but most of them are demonstrated by teachers, and children rarely participate in practice, which shows that the tuning fork is relatively lacking in interaction and fun.

The teaching aids toys in our country pay attention to the aspect of intuitive performance. At present, there is a lack of special teaching aids toys when teaching natural sciences to preschool children and lower grade children. Especially in the teaching process of how sounds are produced, children's cognitive ability cannot be fully exerted only by teachers' dictation. It is because they mainly ignore children's practical ability, and do not integrate theory with practice highly. Therefore, we must design the teaching aids toys according to the basic principles of teaching aids toys, and follow the design of timeliness, flexibility, pertinence, energy saving and environmental protection. ${ }^{[5]}$ Let children better integrate knowledge, not sticking to the framework of popular science education, fully embody the continuity of playing teaching aids and knowledge, and have a higher improvement in the use effect. 


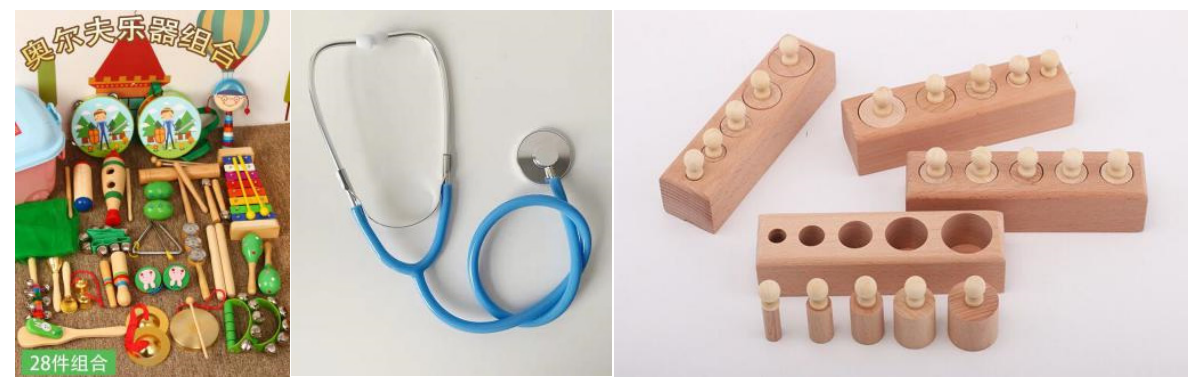

Figure 1: Existing children's voice playing teaching aids.

\section{Children's voice cognition analysis}

\subsection{Children's cognitive analysis of sound}

Hearing is one of the most important human senses. Children 's sensibility to sounds has been from birth. Hearing is an important way for young children to perceive and understand the world. Psychological research shows that children "think with images, colors, and sounds." [6] Voices are everywhere, all the time. Children are very sensitive to changes in voices, and various different voices will attract their attention. Children's perception of timbre starts at 7 months old. Babies can distinguish sounds of different timbre, and can also distinguish synthetic tones of the same pitch containing different melodies. A 4-year-old can analyze synthetic sounds. Children who are 5 to 7 years old can further analyze, but until 9 years old they cannot reach the same level as adults. Children's perception of loudness starts at the age of 5 . At this time, children can express the loudness of the sound with different lengths of the line, reaching the adult level at 8 to 10 years old. Most children aged 5 to 6 years old understand the sound transmission intuitively. Children cannot clearly explain how sound is transmitted. ${ }^{[7]}$ Most children think that the sound is lost through the gap, but they know how to reduce the sound. Very few children can make a more scientific explanation of the way sound is transmitted. For example, sound is generated by the vibration of an object, but they cannot explain the reason.

\subsection{Analysis of sound teaching aids toys}

Everyday our life is full of sounds, and we can hear sounds anytime, anywhere. Sounds are very familiar to us. If children want to understand how sound is produced from the level of knowledge, they can learn and understand the process of sound production during the application of teaching aids toys. To design products, we must explore the generation of sound from the perspective of children, and use the in-depth learning process by teaching aids toys to study sound, so that children can more easily master the skills and mysteries of sound generation, and thus improve children's physical learning literacy. The design and production of sound teaching aids toys is based on the needs of learning content and the premise of interest guidance. It can enhance children's ability to understand and recognize the sound, and then increase the interest in using teaching aids, and get full ability training.

\section{Design method and case design}

\subsection{Design method}

\subsubsection{Mind map}

Mind maps use graphic and graphic techniques to show the relationship between topics at various levels in a subordinate and related hierarchical graph, to establish the memory links between topic keywords and images, colors, etc., and make full use of the functions of the left and right brains ${ }^{[8]}$. Through the mind mapping method, the characteristics of the sound were sorted out to generate design ideas and expand around the main line of sound production. See Figure 1. As a result, the relevant design elements of the sound teaching aids toys are clearly extracted, increasing the multiple possibilities for the innovative design of the sound teaching aids. 


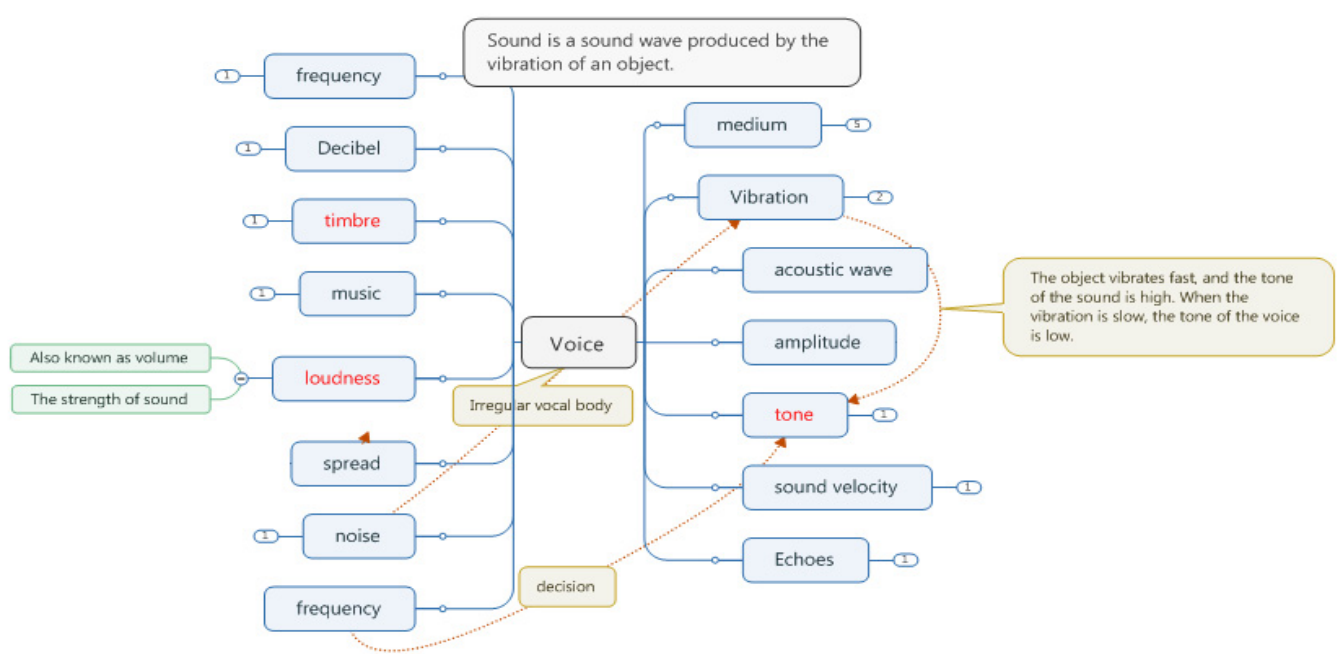

Figure2: Thinking map of audio playing teaching aids.

\subsubsection{Feature enumeration method}

The feature enumeration method uses the method of decomposition and analysis as a most basic creative technique, also known as attribute enumeration method. It is often used to transform and innovate objects. It emphasizes observation, analysis, and discovery of connections. According to the characteristics of the sound as the research object, the design scheme for combing the sound features through the matrix diagram can be designed in the five major fields of teaching aids toys, and they can be combined into a variety of play teaching aid design schemes. We can enumerate a certain feature of the sound, put forward the design idea, and lead to the design plan. See Figure 3.

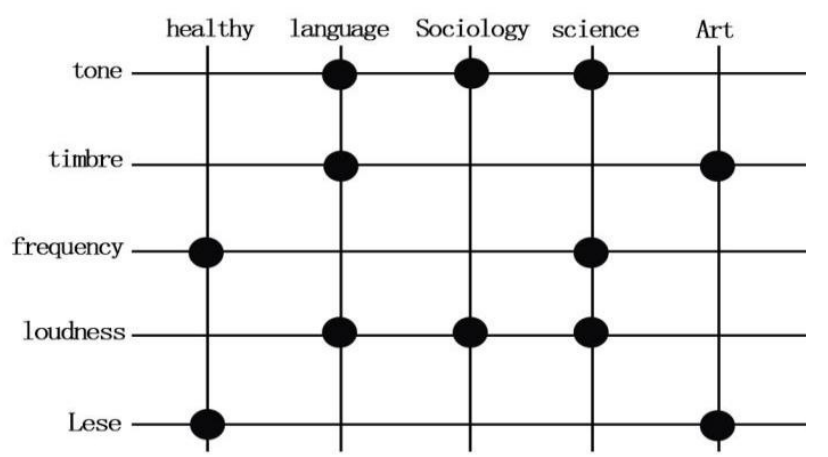

Figure 3: A list of the characteristics of audio playing teaching aids.

\subsection{Design case of sound teaching aids toys}

\subsection{1.}

\section{Design scheme 1: Design of frequency teaching aids toys of "Audio Tumbler"}

Frequency is the number of periodic changes completed per unit time, and is a quantity that describes the frequency of periodic movements. When the tumbler swings from side to side, a periodic motion is performed. During the movement, the shrapnel inside the tumbler starts to sound, and when the vertical vibration stops and the sound stops. The frequency of sound is more intuitively displayed, which is very interesting. The image of musical notes and tuning forks is selected to be closer to the children's visual perception of the sound image. The internal shrapnel sounds when shaking,
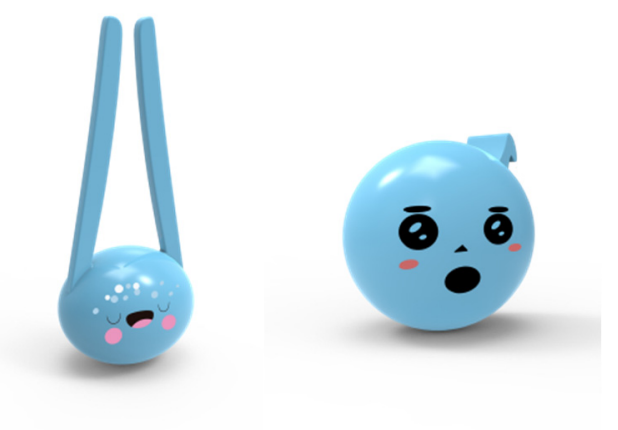

Figure4: “Audio tumbler”Design of teaching aids.

which plays the role of "education and entertainment" when shaking. See Figure 4.

The frequency teaching aids toys "Audio Tumbler" adopts the method of refining the image of notes and tuning forks. The image of notes and tuning forks is deeply rooted in people's hearts. Sound teaching aids toys not only make children recognize the sound, but also make the sound features more intuitive to show. In order to meet the fun and interactive characteristics, combining the sound frequency and the form of sound waves, the sound characteristics are better expressed on the carrier of children's teaching aids toys.

\subsubsection{Design scheme 2: Design of vibrating teaching aids toys of "Simulation of Tympanic Vibration"}

The vibration teaching aids toys "Simulation of tympanic vibration" is the visual image of the ear to reflect the 
vibration of the tympanic membrane, so that children can simulate the vibration of the tympanic membrane in the process of playing, through the amplification method and conversion method to show how the sound produces energy. When uttering to the ear, you can pass through different positions (far and near) and observe the change

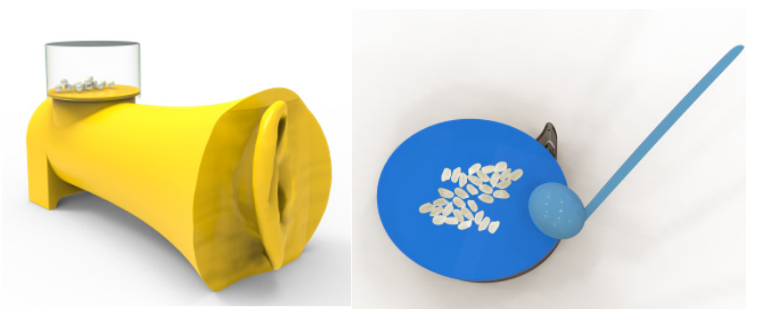

Figure5: "Simulated periosteal vibration"Design of vibrational teaching aids.

The vibration characteristics of the vibration teaching aids toys of "Simulation of Tympanic Vibration" is one of the courses of sound transmission. But "sound" is invisible and intangible. Most children's knowledge about "sound transmission" is difficult to understand clearly and intuitively. Children can only understand through the teacher's oral descriptions in the course, which seriously affects children's learning effect and learning enthusiasm. In order to enable children to intuitively understand the characteristics of sound vibration, the sound vibration characteristics are better expressed on the carrier of children playing teaching aid products.

\subsubsection{Design scheme 3: Design of transmission teaching aids toys "Microphone"}

The design of transmission teaching aids toys "Microphone" is a conical microphone used to increase the volume. The speed of the microphone in the solid body is faster than that in the air. In the middle of the two solid earphones, a water pipe is used to connect the sound waves to cause the solid vibration to transmit sound. The application is realized by means of grouping, which is composed of water pipes, converters, sound tubes and other parts. It is fun and interactive when applied. The first water pipe connected in the middle is an intuitive sound wave form, which means that sound is transmitted by waves. The second section can be played by three or more people, and converts multiple links in the head, greatly increasing children's interactivity. See Figure 6.

\section{Conclusion}

Through the analysis of children's cognition of sounds in different stages, in the course of "How Sounds Are Produced", it is necessary to design interesting and interactive teaching aids toys according to the cognitive of the vertical ball vibration in the transparent cylinder above the simulator. Similarly, the musical hammer hits the blue plastic film, and the rice on it will jump. The above-mentioned teaching aids toys were used to show the vibration of sound. See Figure 5.

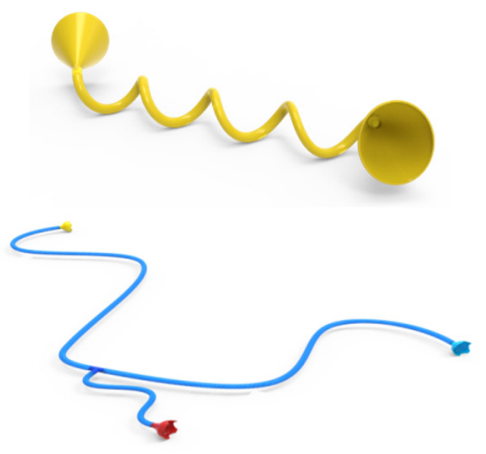

Figure6: "microphone”Design of teaching aids.

characteristics of children of different ages, so that children can more effectively understand relevant knowledge points. Therefore, in the design of teaching aids toys, it is very necessary to analyze the children's cognitive laws of sound, so that children's subjective initiative in the process of using teaching aids toys can be fully exerted, which helps to mobilize children's enthusiasm for learning and achieve "learning while playing" and be happy in learning. At the same time, with the continuous progress of science and technology, the design of teaching aids toys should pay more attention to emerging technologies, so as to be used in the design of teaching aids, and then design teaching aids more in line with modern children.

\section{References}

1. Ke-qiu Z. (1997)Analysis and referenceof science education in foreign primary schools [J].Foreign primary and secondary education., 3:29-30.

2. Hong-ying M. (2016)Exploration on the production of scientific teaching aids in primary schools based on innovative ideas[D].Bohai University.

3. Hong-yun Y. (2009)Playing with sound - large class scientific activities.Shandong Education: Preschool Education., 000:85-86.

4. Shan-shan C.(2018)A study on the simple understanding of voice transmission among children aged 5-6 .Education observation (the last ten days)., 007:51-55.

5. Shuang L.(2012) The value of playing teaching aids in children's development.Art education., 000:192192.

6. Wei D, Cheng-xu W. (2007)Democracy And Education.People's Education Press.Beijing.

7. Ling W.(2015) Design principles and educational value of self-made play teaching aids.Gansu Education., 20:65-65. 
8. Ze-ying H.(2011)Make good use of thought map and build knowledge network[J].Guangdong Education: Comprehensive Edition., 3:48-49. 